the large number of patients whose sputum is infectious before their cases are notified.

Apart altogether from the dirty, and in the majority of cases unnecessary, habit of spitting on public footpaths, it has been pointed out that a by-law which would limit spitting in general would have the desired effect of limiting the special spitting of consumptives in the pre-notification stage; and it has been suggested that, at all events in the first instance, so drastic a measure as the entire abolition of all spitting might be resisted by the general public, while one permitting spitting in the road channels and gullies would be sufficient as a step in the direction of the prevention of indiscriminate spitting. A large amount of information has been obtained from foreign countries as regards spitting on footpaths, and the administration of by-laws made to prevent it. In all cases where such a by-law has been in operation, distinct improvement in the condition of the streets has been noted.

\title{
TUBERCULOSIS AND THE PUBLIC HEALTH SERVICE.
}

\author{
BY SIDNEY DAVIES, \\ M.A., M.D., D.P.H.,
}

Medical Officer of Health of the Metropolitan Borough of Woolwich.

THERE are four ways in which local health authorities and the State may aid in the war against tuberculosis :

I. Regulation of Environment.-General sanitary measures have already largely aided in the reduction of this disease. Drier houses, more cubic space in and about houses, windows which open, are strengthening the resistance of the individual to the attack of tubercle bacilli, though perhaps, as Sir Clifford Allbutt maintains, the cheapness of food during the past fifty years has been a more important factor. We must persevere in both these directions.

2. The Prevention of Infection.-On many points we disagree as to the common sources of infection, but it is well to specially guard against the danger insisted on by Professor Koch and Dr. Newsholme-viz., the infectiousness of advanced cases in poor homes. No pains should be spared to secure isolation of such, and removal to Poor Law infirmaries if necessary.

3. Provision for Treatment.-But next to improved environment and cheap food, sanatorium treatment perhaps promises more than most measures for fighting consumption. Woolwich has for five years main- 
tained municipal beds for open-air treatment, and during that time the phthisis death-rate has fallen much more quickly in Woolwich than in the neighbouring Boroughs, where no such provision is made. For a small expenditure the majority of the patients sent are restored to the status of wage-earners for a longer or shorter period; thus the expenditure is economical. The returned patients are missionaries of open-air treatment; the scheme is educational. Many appear to be completely cured.

4. The Control of the Public-house.-Next to poverty, intemperance and the public-house are the chief allies of tuberculosis. All legislation which reduces the number of public-houses and lessens drinking will be an active factor in the abolition of this scourge. 